\title{
General Entomology/Intomologia Geral Ocorrência de Drosophila suzukii (Matsumura) (Diptera, Drosophilidae) na cultura do pessegueiro, em Farroupilha, na Serra Gaúcha, RS
}

\author{
Fabiane Foppa ${ }^{\bowtie}$, Regina da Silva Borba, Tatiani Secretti, Alex Bortoncello \& Janaína Frare
}

Instituto Federal de Educação, Ciência e Tecnologia do Rio Grande do Sul - Campus Bento Gonçalves

EntomoBrasilis 11 (3): $178-184$ (2018)

\begin{abstract}
Resumo. Recentemente, foi encontrada no Rio Grande do Sul, a praga quarentenária Drosophila suzukii (Matsumura) (Diptera, Drosophilidae), praga polífaga que coloca ovos em frutos sadios e intactos. O objetivo do trabalho foi realizar o monitoramento de D. suzukii na cultura do pessegueiro, no município de Farroupilha, RS, bem como verificar a ocorrência e infestação da praga em frutos desta espécie. Foram instaladas duas armadilhas "caça-moscas" na área, contendo vinagre de maçã como atrativo alimentar. Foi estudada a flutuação populacional e a razão sexual de D. suzukii. No final da colheita foram coletados na área, 50 frutos de cada tratamento: plantas da borda do pomar (T1), plantas do interior do pomar (T2), frutos caídos no solo na borda do pomar ( $\mathrm{T}_{3}$ ) e frutos caídos no solo no interior do pomar (T4). Os frutos foram acondicionados individualmente por 50 dias, até que todos os adultos emergissem, sendo, então, identificados e sexados. A flutuação populacional de adultos de $D$. suzukii mostrou um aumento no número de indivíduos com o início da maturação dos frutos. $\mathrm{O}$ tratamento $\mathrm{T} 4$ foi o que apresentou o maior número de adultos de $D$. suzukii emergidos, seguido do tratamento T3. Já nos tratamentos T1 e T2 não apresentaram emergência de adultos. Esses resultados mostram que provavelmente a fêmea de $D$. suzukii não consegue ovipositar em frutos de pêssego, devido a sua pele aveludada, no entanto, o pêssego pode servir como hospedeiro alternativo.
\end{abstract}

Palavras-chave: Monitoramento; mosca-da-asa-manchada; mosca-da-cereja; pêssego; praga quarentenária.

\section{Occurrence of Drosophila suzukii (Matsumura) (Diptera, Drosophilidae) in the Peach orchards, Farroupilha, RS}

\begin{abstract}
It was recently found in Rio Grande do Sul the quarantine pest Drosophila suzukii (Matsumura) (Diptera, Drosophilidae), a polyphagous pest which lays eggs in healthy and intact fruits.The aim of the study was to monitor the occurrence of D. suzukii in peach orchards in the city of Farroupilha as well as to verify the infestation of the pest in peach fruits. Two traps "flapper" were installed in the area, containing apple cider vinegar as food bait.The population fluctuation and the sex ratio of D. suzukii was set. At the end of harvest there were collected in, 50 fruit each treatment: plants on the border of the orchard (T1), plants in the interior of the orchard (T2), fallen fruits on the ground at the orchard board (T3), and the fallen fruits on the ground in the interior of the orchard ( $\left.\mathrm{T}_{4}\right)$. The fruits taken individually packed for 50 days, until all the adults emerge, and then they were identified and sexed. The population fluctuation of $D$. suzukii adults showed an increase in the number of individuals with the beginning of the fruit maturation. Treatment $\mathrm{T}_{4}$ was the one with the highest number of $D$. suzukii adults emerged, followed by the treatment $\mathrm{T}_{3}$. On the T1 and T2 treatments, there were no adults emergence. These results show that probably the females of $D$. suzukii can not lay eggs in peach fruit due to its velvety skin. However, peach can serve as an alternative host.
\end{abstract}

Keywords: Cherry fly; monitoring; peach; quarantine pest; spotted wing drosophila.

$\mathbb{N}$ o Brasil, atualmente a fruticultura é uma atividade de grande importância, sendo que, a área colhida de pêssego, no país, em 2014, foi de aproximadamente 18.206 hectares, atingindo uma produção de 211.109 toneladas da fruta, sendo que a região Sul é responsável por 159.589 toneladas (IBGE 2014).

Segundo FACHINELLo et al.(2011), os principais estados produtores de pêssego são Rio Grande do Sul, o qual é responsável por 65,1\% da produção, em segundo lugar o estado de São Paulo com 14,0\%, seguido por Minas Gerais representando 11,8\%, Paraná com $7,5 \%$ e Santa Catarina contribuindo com 1,6\%.
O estado do Rio Grande do Sul, considerado o maior estado produtor, possui uma área colhida de 13.084 hectares, tendo uma produção de 127.936 toneladas de pêssego, parte desta produção concentra-se no município de Farroupilha, localizado na Serra Gaúcha, onde foram colhidas 8.784 toneladas em área de 610 hectares (IBGE 2014).

A Encosta Superior do Nordeste do estado do Rio Grande do Sul é a principal região produtora de pêssegos para consumo in natura do estado, e a presença de Drosophila suzukii (Matsumura) (Diptera, Drosophilidae), na cultura do pêssego, seria bastante problemática para a produção, uma vez

\section{Edited by:}

Anderson Gonçalves da Silva

\section{Article History:}

Received: 02.11.2018

Accepted: 30.x.2018
Corresponding author:

Fabiane Foppa

fabi foppa@hotmail.com

(\$) https://orcid.org/o0oo-0002-2662-6437
Funding agencies:

$\leftrightarrow$ Without funding declared 
que a produção da fruta já sofre danos pela mosca-das-frutas Anastrepha fraterculus (Wiedemann) (Diptera: Tephritidae), uma das principais pragas da fruticultura brasileira, em especial do pessegueiro (NAVA \& BotTon 2010).

Segundo Bruno (2014), a espécie D. suzukii foi descrita por Matsumura, em 1931, sendo que os primeiros relatos de danos ocorreram no Japão e foram mencionadas por Kanzawa em 1939, nas culturas de cerejas, uvas, pêssegos, maçã, caqui e ameixas.

A espécie D. suzukii é conhecida no exterior como Spotted Wing Drosophila (SWD), possuindo elevada capacidade de dispersão, a praga tem se alastrado rapidamente em países da Europa e América do Norte (SANTOS 2014a).

No Brasil, a espécie-praga $D$. suzukii foi recentemente registrada no Rio Grande do Sul quando foram coletados exemplares em um horto florestal do município de Capão do Leão e, em três reservas biológicas do estado de Santa Catarina. Apesar disso, ainda não existia registros da praga atacando espécies frutíferas, porém, em janeiro de 2014, um produtor relatou perda de $30 \%$ da produção de morangos, por danos de D. suzukii na cidade de Vacaria, RS. A espécie D. suzukii infesta grande diversidade de frutos, sobretudo aqueles de pele fina (SANTOS 2014a, 2014b).

Originária do Japão a $D$. suzukii é uma praga quarentenária polífaga, de reduzido tamanho corporal $(2-3 \mathrm{~mm}$ de comprimento), elevada capacidade de dispersão e que coloca seus ovos no interior de frutos sadios e intactos (Santos 2014a). Possui tórax de coloração amarelada a marrom pálido, com faixas pretas longitudinais ao longo do abdômen e com olhos vermelhos (SCHLESENER et al. 2015).

Conforme TeIXeIRA \& REgo (2011), a D. suzukii pode infestar uma grande diversidade de frutos, sobretudo os de pequena dimensão. Existem registos de danos significativos em morangos, mirtilos, amoras, framboesas, cerejas, ameixas, pêssegos e damascos. Em pessegueiros, apesar de haver poucos registros de perdas em pomares localizados no centro de origem da praga, há relatos de danos econômicos significativos nos EUA, na ordem de $20 \%$ (CPAN 2009).

Os machos são facilmente identificáveis, por apresentarem uma pequena mancha negra no ápice das asas, característica marcante desta espécie e possuir ainda uma linha de cerdas no primeiro e no segundo segmento tarsal, do primeiro par de pernas, conhecida como pente tarsal. No caso das fêmeas, a identificação é mais difícil sendo que estas, não apresentam manchas alares e pode ser confirmada pela forma característica do ovipositor, que é longo, estreito e duplamente serreado, com capacidade de depositar ovos no interior de frutos fixados à planta (Teixeira \& Rego 2011; Bruno 2014; SANtos 2014a; Bruno 2014; SCHLESENER et al. 2015).

Os ovos de $D$. suzukii são branco leitoso e possuem uma dimensão de o,6 milímetros de comprimento e apresentam dois filamentos respiratórios, na porção terminal de uma das extremidades (geralmente a única parte visível do ovo) (SCHLESENER et al. 2015).

As larvas, igualmente aos ovos são brancas e permanecem no interior do fruto até à pupação, que pode ocorrer no interior ou na superfície do fruto ou no solo. Possuem forma cilíndrica e suas dimensões variam de 0,067 a 3,5 milímetros de comprimento, sendo que, as larvas apresentam 3 instares (Teixeira \& Rego 2011; Bruno 2014; SCHLESENER et al. 2015). A cor das pupas varia de amarela acinzentada a castanha (TEIXEIRA \& REGO 2011). Segundo ALsTon et al. (2010), as pupas têm forma cilíndrica e apresentam dimensão de 2 a 3 milímetros de comprimento.

Segundo SCHLESENER et al. (2015), a maturidade sexual da fêmea é alcançada em 1 ou 2 dias, se sob condições favoráveis de temperatura e umidade, sendo o tempo máximo registrado de 13 dias.

O período de incubação dos ovos de D. suzukii é de 2 a 72 horas, podendo variar conforme temperatura e hospedeiro. Após a incubação dos ovos ocorre a eclosão das larvas, as quais atingem o último instar em 3 a 13 dias, sendo que estas se desenvolvem no interior do fruto, alimentando-se da polpa e o período de pupa varia de 3 a 15 dias (BRUNo 2014; SCHLESENER et al. 2015).

A longevidade dos adultos varia entre 21 a 66 dias, sendo que para se mensurar o tempo do ciclo de $D$. suzukii, deve ser levada em consideração a temperatura, como um fator de extrema importância, sendo que o tempo mínimo entre oviposição e a emergência é de 8 dias e a média de tempo estimado é entre 8 e 18 dias (BRuno 2014; SCHLESENER et al. 2015).

SCHLESENER et al. (2015), relatam que D. suzukii vem sendo considerada uma das principais pragas de frutos com epiderme fina, em diversos países, sendo capaz de atacar uma série de frutos nativos ou exóticos. Os registros existentes, com danos significativos, são referentes às seguintes culturas: ameixa (Prunus sp.), amora (Rubus sp.), caqui (Dios pyruskaki), cereja (Prunus sp.), damasco (Prunus armeniaca L.), framboesa (Rubus idaeus L.), mirtilo (Vaccinium myrtillus L.), morango (Fragaria sp.) e pêssego [Prunus pérsica (L.)], ocorrendo ainda em menores proporções em figo (Ficus sp.), Kiwi (Actinidia sp.), uva (Vitis sp.), laranja (Citrus sp.) e maçã (Malus sp.)

Conforme SANTos (2014a), os danos primários de D. suzukii são causados pelas fêmeas quando estas perfuram a superfície da fruta para depositar os ovos e, posteriormente, pelas larvas que se alimentam da polpa das frutas. Sendo que, os danos secundários aparecem posteriormente, e são causados por microrganismos como fungos e bactérias, que se desenvolvem a partir dos orifícios da oviposição, os quais contribuem de forma ativa na deterioração dos frutos, deixando-os impróprios para a comercialização (BRUNO 2014).

Conforme Schlesener et al. (2015), além dos danos causados pela alimentação das larvas no interior do fruto e da inserção do ovipositor, ocorre ainda uma depreciação da qualidade do fruto como um todo, diminuindo assim, a sua vida pós-colheita.

A dispersão do inseto-praga é feita através do voo dos adultos de $D$. suzukii ou da circulação de frutos contendo larvas e/ou pupas em curtas distâncias (propriedade) ou longas distâncias (mercados consumidores de frutas) (SANTOS 2014b).

Segundo SANTos (2014a), existem registros de captura da $D$. suzukii, porém ainda não existe ferramenta eficaz para o monitoramento da praga. Esse fato pode estar relacionado à biologia da praga, uma vez que, ao contrário de outros drosofilídeos, que completam o ciclo no mesmo hospedeiro em fermentação, a espécie de D. suzukii, para realizar a oviposição, necessita de frutas sem danos e em maturação. Dessa forma, é provável que o odor produzido pela fermentação de frutas represente apenas uma indicação de atrativo genérico para monitoramento, uma vez que as fêmeas fertilizadas têm nos voláteis de frutas frescas seu alvo para oviposição.

Conforme Schlesener et al. (2015), para o sucesso do monitoramento é necessário observar fatores como, formato e estrutura da armadilha. As armadilhas devem ser colocadas em locais sombreados, ou seja, que não tenha incidência direta do sol. As armadilhas do tipo McPhail, podem ser utilizadas no monitoramento, a qual apresenta bons resultados, facilitando a entrada da D. suzukii, e a dispersão do odor da isca.

Inúmeros estudos estão sendo realizados com o objetivo de testar diferentes atrativos para captura de D. suzukii. Conforme SCHLESENER et al. (2015), compostos como melaço, vinagre de arroz, óleos essenciais, açúcar e suco de cereja foram testados 
em diferentes concentrações, para atratividade de $D$. suzukii, porém, o resultado satisfatório foi encontrado na isca composta por vinagre de maçã e vinho tinto.

Como atrativo alimentar, para utilização nas armadilhas, TEIXEIRA \& REgo (2011), recomendam como isca uma mistura de fruta muito madura composta por, pelo menos, $50 \%$ de banana e o restante por fruta da época. Porém, conforme SANTos (2014a), até que sejam obtidos atrativos mais eficientes, sugere-se a utilização de vinagre de maçã puro.

Por ser uma praga quarentenária e apenas recentemente ter sido detectada a sua presença no país, ainda não há nível de dano econômico e nem produtos registrados para D. suzukii no Brasil, salienta SANTOS (2014a).

No Rio Grande do Sul, a ocorrência dessa praga quarentenária surge como alerta aos fruticultores e pesquisadores, sendo que existem poucas informações em relação a esta espécie para as condições da Serra Gaúcha. Desta maneira o objetivo do trabalho foi realizar o monitoramento de adultos de $D$. suzukii em pêssego da cultivar Chimarrita, no município de Farroupilha, na Serra Gaúcha, bem como verificar a ocorrência e infestação da praga em frutos de pêssego.

\section{MATERIAL E MÉTODOS}

Monitoramento de $D$. suzukii em pomar de pessegueiro. O trabalho de pesquisa foi realizado em uma propriedade rural localizada na cidade de Farroupilha, na Serra Gaúcha, RS, no ano agrícola 2015/2016.

O monitoramento para a detecção da ocorrência de $D$. suzukii foi realizado em uma área com pomar comercial de pessegueiros, da cultivar Chimarrita que representa uma área de um hectare, conforme Figura 1.

O monitoramento de adultos de $D$. suzukii foi realizado através da instalação de duas armadilhas "caça-mosca" na área. Conforme recomendado por SANTOS (2014a), as armadilhas foram confeccionadas com garrafa PET pequena (250 mL), contendo entre cinco e sete furos de $5 \mathrm{~mm}$ posicionados equidistantes (acompanhando o perímetro do frasco) no seu terço inferior, conforme Figura 2. Como atrativo alimentar foi utilizado vinagre de maçã puro, durante todo o experimento, conforme recomendado por GERDEMAN (2011).

O monitoramento foi realizado desde a formação dos frutos até a época de colheita, sendo que, este período foi compreendido entre o dia primeiro de setembro a 19 de dezembro de 2015. Conforme Teixeira \& Rego (2011), o monitoramento de $D$. suzukii deve iniciar um a dois meses antes do amadurecimento dos frutos.

As armadilhas foram instaladas no interior do pomar, conforme recomendação de Dreves \& Langellotto-Rhodaback (2011), ou seja, para frutas de caroço, recomenda-se que as armadilhas sejam colocadas no dossel da planta, ao nível dos frutos e no lado mais sombreado da planta.

As armadilhas foram vistoriadas duas vezes por semana, quando os exemplares foram coletados e o atrativo alimentar trocado.

Os insetos coletados foram acondicionados em frascos contendo álcool 70\% e levados para o Laboratório de Entomologia do Instituto Federal de Educação, Ciência e Tecnologia, campus Bento Gonçalves (IFRS-BG), onde foram identificados.

A identificação foi baseada na morfologia externa e análise da genitália dos adultos, ou seja, para a identificação dos machos foi observada a mancha escura nas asas, e para a identificação das fêmeas observou-se o ovipositor duplamente serrilhado, para isto, utilizou-se uma lupa binocular estereoscópica com $5 \mathrm{x}$ de aumento. Utilizou-se ainda, exemplares da espécie fornecidos pela Embrapa Uva e Vinho, Estação Experimental de Fruticultura de Clima Temperado, Vacaria, RS, para auxiliar na identificação.

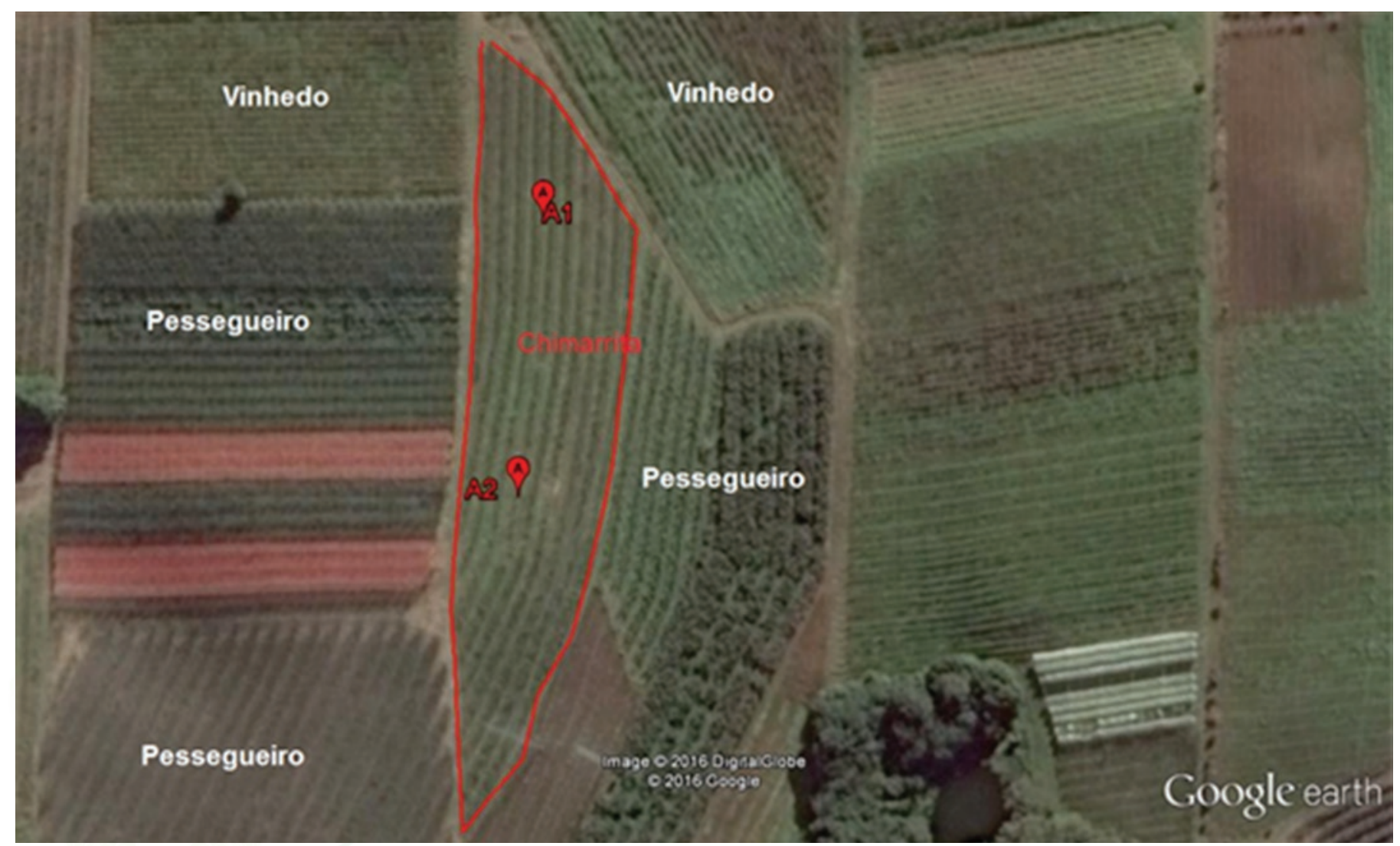

Figura 1. Disposição das armadilhas em área com pessegueiros da cultivar Chimarrita, onde foi realizado o monitoramento de D. suzukii. Farroupilha, RS, 2015. Fonte: Google Earth, 2016. 


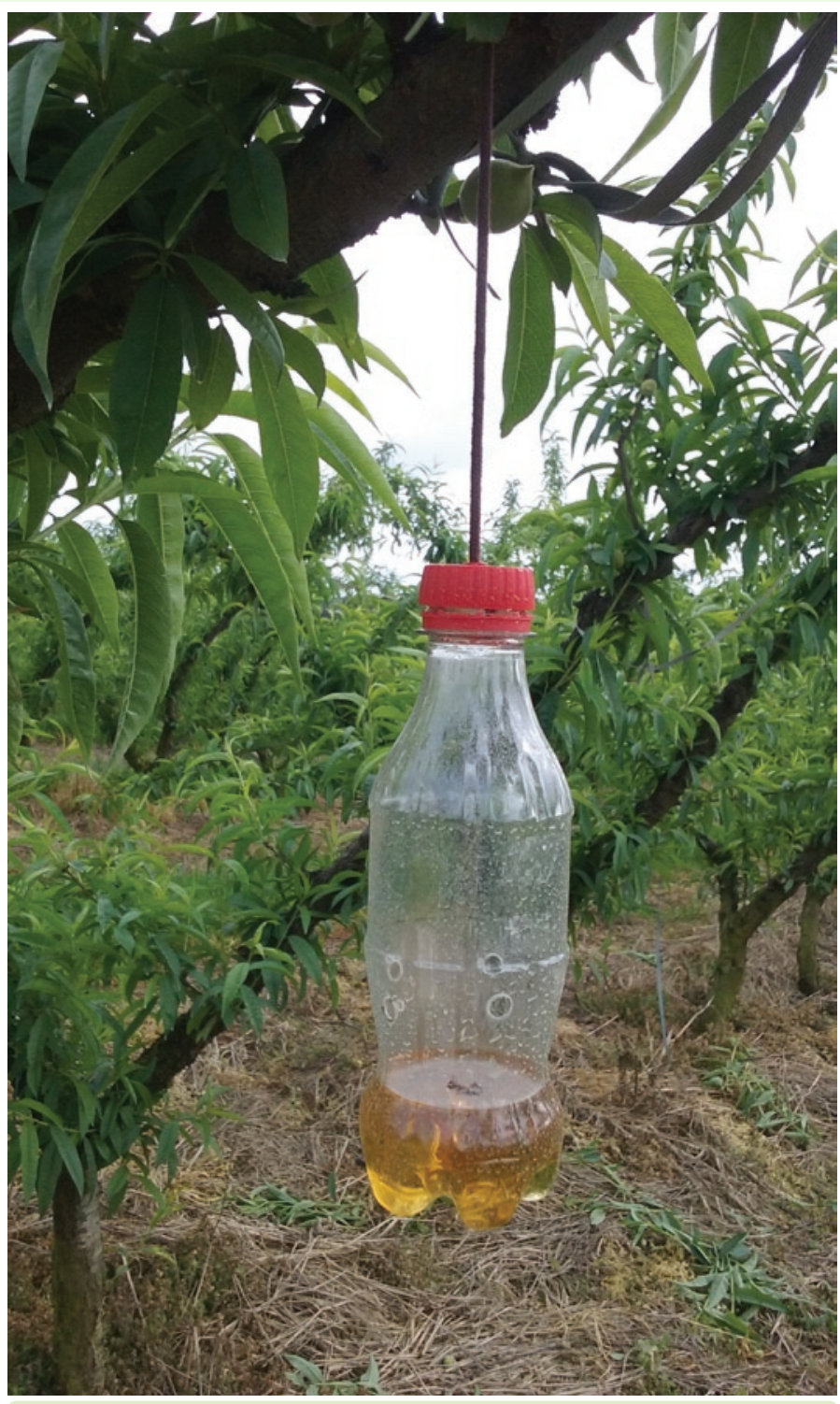

Figura 2. Armadilha "caça-mosca" para captura de D. suzukii, instalada em pomar de pessegueiro da cultivar Chimarrita. Farroupilha, RS, 2015 .

Os insetos coletados foram analisados individualmente, sendo que os adultos identificados como $D$. suzukii foram sexados e computados para cada armadilha. Sendo que, a razão sexual foi calculada através da divisão do número de fêmeas pelo total de indivíduos (machos + fêmeas), conforme metodologia de Silveira-Neto et al. (1976).

Com a obtenção dos dados do monitoramento foi elaborado um gráfico demonstrando a flutuação populacional de $D$. suzukii na área.

Durante a realização do trabalho de pesquisa foram realizados os tratamentos fitossanitários convencionais da propriedade. Sendo que, neste período foram realizadas duas aplicações de inseticidas, uma realizada no mês de setembro com Actara (tiametoxam: neonicotinóide) e outra no mês de outubro com Decis (deltrametrina: piretróide). As aplicações foram realizadas para o controle de Anastrepha fraterculus (Wiedemann), Grapholita molesta (Busck) e Myzus persicae Sulzer.

Os dados climáticos de temperatura e precipitação que ocorreram na região durante o período de monitoramento foram registrados pela estação meteorológica automática, da Embrapa Uva e Vinho, de Bento Gonçalves.

Ocorrência de $D$. suzukii em frutos de pêssego. Ao final da safra, foram coletados frutos maduros de pêssegos, com o intuito de verificar a ocorrência de insetos de D. suzukii. Estes frutos foram coletados, em uma área de um hectare, de pomar comercial da cultivar Chimarrita, localizado no município de Farroupilha, onde estava ocorrendo o monitoramento da praga.

$\mathrm{Na}$ oportunidade foram coletados aleatoriamente 200 frutos de pêssego, sendo estes divididos em quatro tratamentos compostos por 50 frutos (cada fruto representou uma repetição) de cada tratamento: frutos das plantas localizadas na borda do pomar (T1), frutos das plantas localizadas no interior do pomar (T2), frutos caídos no solo na borda do pomar ( $\left.\mathrm{T}_{3}\right)$ e frutos caídos no solo no interior do pomar (T4).

Os frutos foram acondicionados em caixas de plástico e levados ao laboratório do Instituto Federal de Educação, Ciência e Tecnologia, campus Bento Gonçalves (IFRS-BG), onde foram acondicionados individualmente em potes de plástico transparentes, com capacidade de $700 \mathrm{~mL}$, conforme metodologia adaptada de Souza Filho (2006). Os potes foram identificados em tratamentos ( $\mathrm{T} 1, \mathrm{~T} 2, \mathrm{~T} 3$ e $\mathrm{T} 4$ ), bem como com o número de repetições, sendo estas compreendidas de um à cinquenta.

Na base dos potes, colocou-se uma fina camada de vermiculita (Figura 3) com o objetivo de reter umidade e/ou pupação dos insetos, conforme metodologia de SANTos (2014a). Cada pote

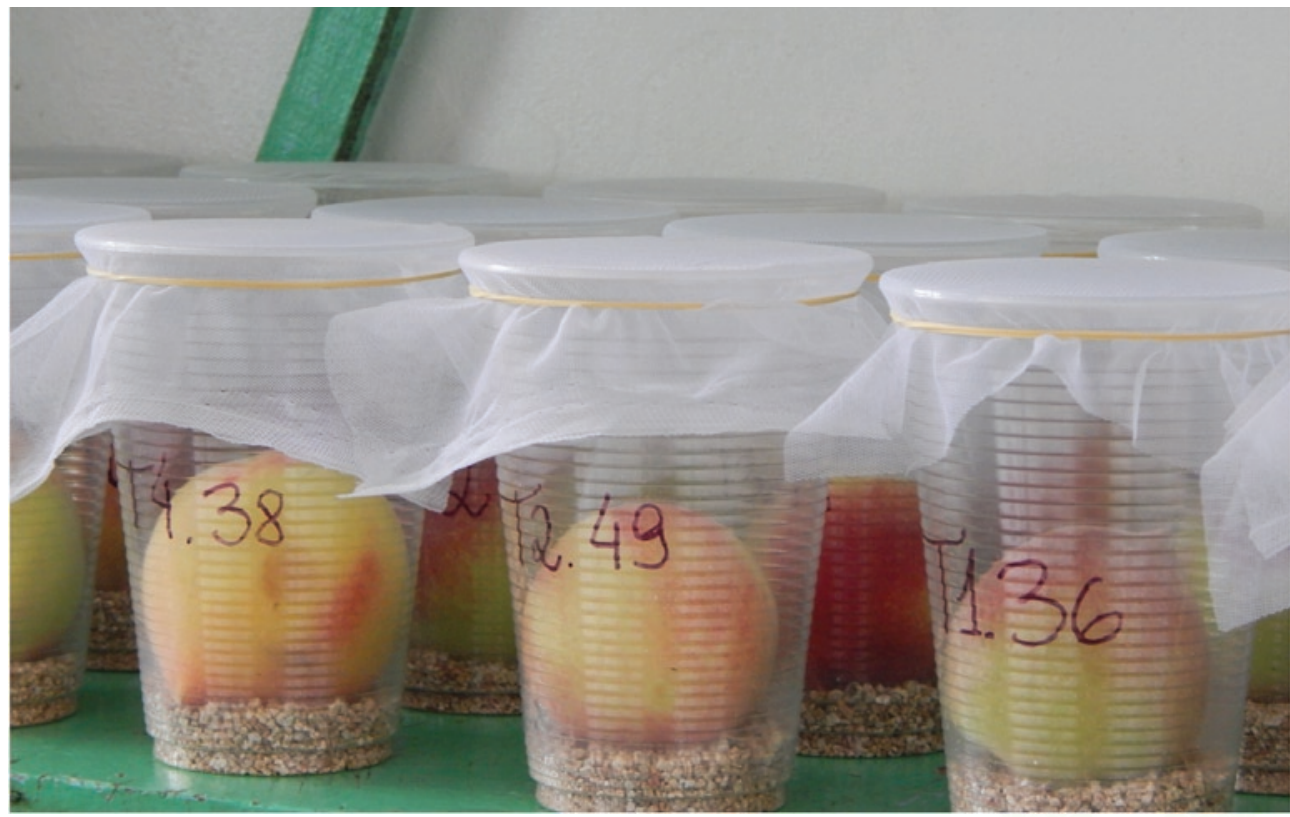

Figura 3. Detalhe do experimento com os frutos de pêssego acondicionados individualmente em pote plástico descartável com capacidade de 70o $\mathrm{mL}$, com uma camada de vermiculita ao fundo e coberto com "voil" preso por elásticos de látex. 
foi coberto com tecido "voil", e fixado com o auxilio de elásticos de látex, para evitar a fuga de adultos emergentes. Cada pote, contendo o fruto, foi disposto em estante de madeira, sendo que, a distribuição ocorreu aleatoriamente, através de sorteio.

O trabalho foi conduzido com temperatura de $24 \pm 3^{\circ} \mathrm{C}$ e umidade relativa de $75 \pm 20 \%$. Os frutos foram mantidos nestas condições por 50 dias, até que todos os adultos emergissem, sendo que, os insetos eram retirados, e analisados, para evitar a decomposição dos mesmos.

Os potes que possuíam adultos vivos foram colocados por 10 min. em ultrafreezer (temperatura de $-77^{\circ} \mathrm{C}$ ). Após este período os insetos foram retirados do interior dos copos com o auxilio de pinças e acondicionados em frascos de vidro individualmente contendo álcool $70 \%$ para posteriormente serem identificados, computados e sexados.

O delineamento experimental realizado foi inteiramente casualizado com 4 tratamentos e 50 repetições. Os dados obtidos foram submetidos à análise de variância e as médias comparadas pelo teste de Tukey a $5 \%$ de probabilidade, utilizando o programa estatístico SASM-Agri (CANTERI et al. 2001).

\section{RESULTADOS E DISCUSSÃO}

Monitoramento de $D$. suzukii em pomar de pessegueiro. Durante o monitoramento foi constatada a presença de D. suzukii na cultura do pessegueiro da cultivar Chimarrita, no pomar comercial localizado em Farroupilha, na Serra Gaúcha. Assim como relatado por SchlESENER et al. (2015), onde na região sul do Rio Grande do Sul, obteve-se coleta de D. suzukii em pomares de pessegueiros através de armadilhas do tipo McPhail, com proteína hidrolisada.

A captura de D. suzukii, no pomar de pessegueiro ocorreu desde a primeira semana de monitoramento (01 a 05/09/2015), conforme mostra a Figura 4. A captura de insetos foi crescente, ou seja, aumentando o número de insetos coletados, conforme desenvolvimento e amadurecimento dos frutos de pêssego, conforme observaram LEE et al. (2011), que ao oferecerem cerejas verdes, em inicio de maturação e completamente maduras à $D$. suzukii, observaram que a preferência para a oviposição foi de 11\%, 34\% e 55\%, respectivamente. Segundo BRUNO (2014), a punctura ocorre preferencialmente em frutos maduros, mas podem ocorrer em menor proporção em frutos verdes ou em fase de maturação, devido ao ovipositor duplamente serrilhado, permitindo perfurar epidermes mais resistentes.

Conforme SchlESENER et al. (2015), as fêmeas preferem frutos em estágio de amadurecimento mais avançado, se comparado com frutos verdes. O que pode explicar este comportamento é a dificuldade que as larvas de $D$. suzukii apresentam em completar o ciclo em frutos muito ácidos (MALGUASHCA et al. 2010).

O pico de captura ocorreu na semana de 8 a 14 de novembro, onde a média de insetos capturados por armadilha foi de 50,5 adultos (Figura 4), sendo que neste período os frutos estavam em fase de maturação, considerando que a primeira colheita ocorreu na data de 11 de novembro. As fêmeas procuram ativamente frutos em maturação para realizarem as suas posturas. Geralmente, são colocados de 1 a 3 ovos por fruto. Durante o seu tempo de vida, uma fêmea pode colocar 300-400 ovos (TEIXEIRA \& REGO 2011).

Após a primeira quinzena de novembro, as capturas foram decrescentes, este fato pode estar relacionado com a aplicação do inseticida Decis (deltrametrina: piretróide) realizada no pomar, sendo que isto pode ter ocasionado a mortalidade de adultos de D. suzukii na área. Conforme Schlesener et al. (2015), o controle químico é o método de controle mais utilizado em locais onde há ocorrência de $D$. suzukii, sendo que, os piretróides apresentam bons resultados no controle por contato e poder residual sobre a praga, nas culturas da cerejeira, framboeseira, mirtileiro, morangueiro e videira. Contudo, no Brasil não há produtos registrados para o controle da praga (SANTOS 2014a).

Além disso, devido a realização da primeira colheita dos frutos, a partir desta data, no interior do pomar os frutos com injúrias, danos, e/ou processo de amadurecimento avançado, estavam caídos no solo, o que pode ter atraído os insetos para estes frutos, diminuindo assim, a captura de adultos nas armadilhas. Conforme BRUNo (2014), para reduzir a probabilidade de ataque de $D$. suzukii, deve-se levar em consideração algumas práticas agrícolas, como remover qualquer fruto da planta ou do solo, evitando a praga a efetuar puncturas nestes frutos. Estes frutos removidos do pomar devem ser destruídos, sendo que a forma mais eficaz é a colocação dos frutos em recipientes fechados e posterior dissecação (solarização). A técnica da compostagem não é recomendada podendo agravar o problema, uma vez que as larvas são capazes de se desenvolver no processo de decomposição (WALSH et al. 2011).

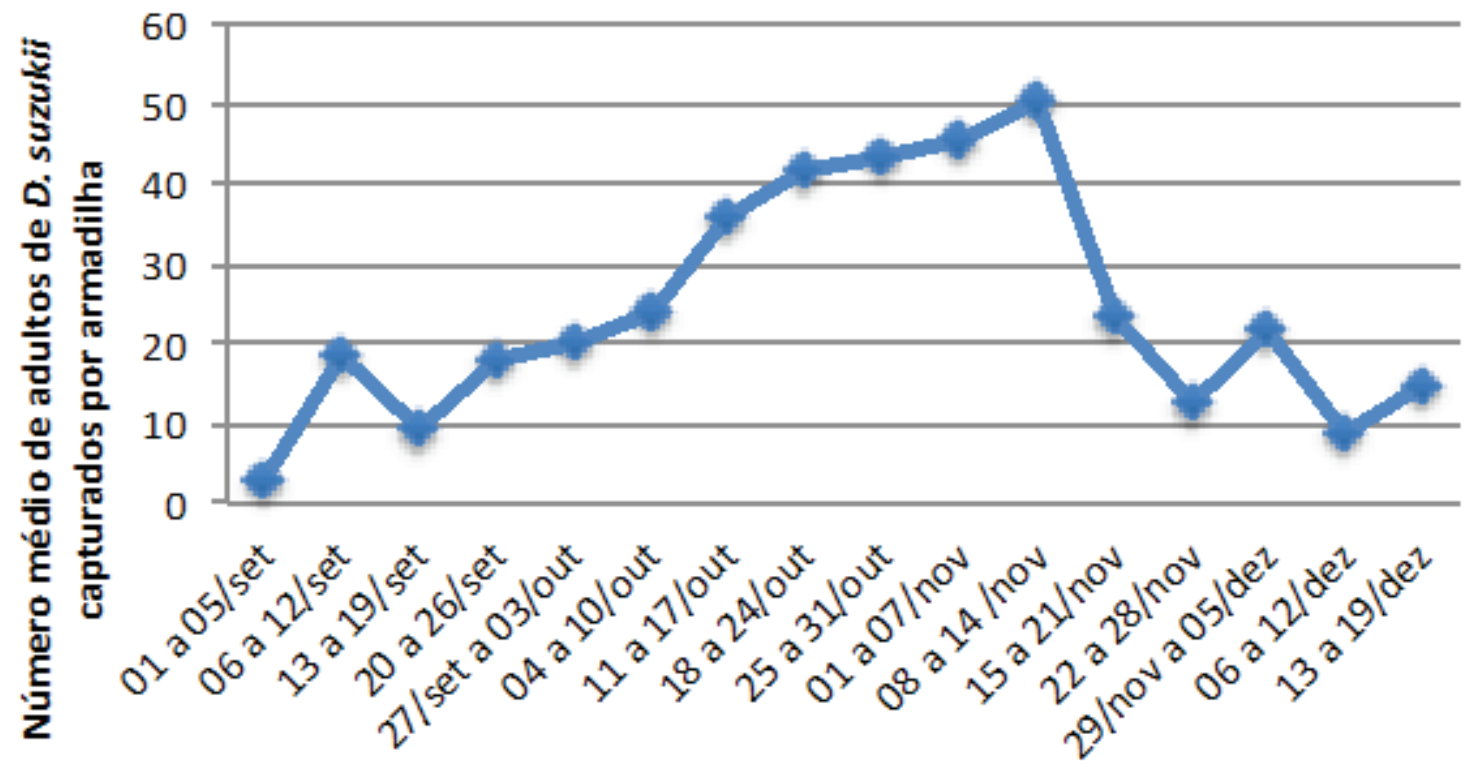

Semanas de monitoramento

Figura 4. Flutuação populacional de adultos de D. suzukii em pomar de pessegueiro da cultivar Chimarrita, no município de Farroupilha, RS, 2015. 
Em relação à razão sexual de adultos de $D$. suzukii capturados durante todo o período de monitoramento, houve uma maior proporção de fêmeas do que de machos, demonstrando uma razão sexual de 0,98, conforme mostra a Tabela 1. Concordando com SANTOS (2014b), que analisando frutos de morangueiro atacados por $D$. suzukii, no município de Vacaria, encontrou maior número de fêmeas em relação aos machos. Mas, diferindo de Bortoncello et al. (2015), que avaliando ocorrência de $D$. suzukii em pomar comercial de pessegueiro no município de Cotiporã, encontraram maior número de machos do que fêmeas nas armadilhas. Assim como, LeE et al. (2012) que ao realizar monitoramento da praga na cultura do pessegueiro no Canadá, encontraram maior quantidade de machos do que de fêmeas.

Tabela 1. Razão sexual de adultos de D. suzukii capturados em pomar de pessegueiro da cultivar Chimarrita, no município de Farroupilha, RS, 2015 .

\begin{tabular}{ccc}
\hline Fêmeas & Machos & Razão Sexual \\
\hline 765 & 14 & 0,98 \\
\hline
\end{tabular}

Os dados de precipitação e temperatura durante o período de monitoramento não influenciaram na flutuação populacional de D. suzukii, conforme anexo A.

D. suzukii possui preferência por temperaturas amenas, porém segundo BRUNo (2014), em temperaturas abaixo de $5^{\circ} \mathrm{C}$, os insetos cessam seu desenvolvimento, começando a ter alguma atividade $\operatorname{aos} 10^{\circ} \mathrm{C}$ e maior atividade aos $20^{\circ} \mathrm{C}$, voltando a baixar o nível de atividade ao atingir $30^{\circ} \mathrm{C}$. Sendo assim, seu melhor desempenho reprodutivo ocorre em temperaturas entre $20^{\circ}$ $\mathrm{C}$ a $25^{\circ} \mathrm{C}$, preferencialmente com níveis de umidade alta, tais condições climáticas são típicas em regiões de Clima Temperado no Brasil, em especial, a região da Serra Gaúcha.

Ocorrência de $D$. suzukii em frutos de pêssego. Durante o período de 50 dias, nos quais, os frutos foram mantidos em laboratório, o tratamento utilizando frutos caídos no solo no interior do pomar (Tratamento 4), foi o que apresentou o maior número de adultos de $D$. suzukii emergidos, sendo que em média obteve-se 10,74 adultos por fruto. O tratamento com frutos caídos no solo na borda do pomar (Tratamento 3), também apresentou emergência de adultos, sendo este em menor número se comparado ao Tratamento 4 (Tabela 2).

Os tratamentos com frutos coletados das plantas nas bordas do pomar (Tratamento 1) e com frutos coletados das plantas no interior do pomar (Tratamento 2) não apresentaram emergência de adultos de $D$. suzukii (Tabela 2).

Assim como SAntos et al. (2016), avaliando ocorrência de $D$. suzukii, em pomar de macieira no município de Vacaria, relata que dos frutos coletados a campo, apenas foi possível evidenciar

posturas da praga em frutos com danos na epiderme, sendo estes oriundos de insetos-praga ou rachaduras.

Concordando com Stewart et al. (2014), que ao trabalhar com frutos de pêssego, observaram que frutos sem danos externos não possuíam posturas de $D$. suzukii, porém, em frutos que possuíam algum dano externo verificaram a presença de posturas da praga.

Ainda, BELLAMY et al. (2013), relatam que não foram encontrados adultos de $D$. suzukii emergindo de frutos de pêssego, concluindo que a superfície aveludada do pêssego pode ser a sua defesa mais importante em relação à oviposição de fêmeas de $D$. suzukii, com frutos intactos se mostrou ser um hospedeiro pobre, mas frutos com ferimentos tornam-se hospedeiros aceitáveis. Essa maior atratividade pode acontecer também pela liberação de compostos voláteis que são produzidos por frutos danificados.

A razão sexual da praga ficou entre 0,65 e 0,89 , indicando uma quantidade bem maior de fêmeas do que de machos nos Tratamentos 3 e 4, respectivamente (Tabela 3). Concordando com os resultados de razão sexual, obtidos durante o período de monitoramento no pomar.

Os resultados obtidos evidenciam que $D$. suzukii está presente na cultura do pêssego, porém como praga secundária, ou seja, necessita de ferimentos ou danos primários na epiderme do fruto, para possibilitar a introdução do ovipositor. Provavelmente a fêmea de $D$. suzukii não consegue ovipositar em frutos de pêssego, devido a sua pele aveludada. No entanto, o pêssego pode servir como hospedeiro alternativo, já que a espécie pode se multiplicar facilmente nos frutos que estão caídos no solo.

Durante o período de monitoramento foi constatada a presença de adultos de $D$. suzukii, na cultura do pessegueiro na cultivar Chimarrita, no município de Farroupilha. Entretanto, o fato de ter sido verificada a ocorrência da espécie na cultura, não significa que D. suzukii esteja atacando o pêssego. A praga completa o ciclo em frutos de pêssego, porém, necessita de alguma injúria no fruto para realizar a oviposição. No entanto, o pêssego pode servir como hospedeiro alternativo, já que a espécie pode se multiplicar facilmente nos frutos que estão caídos no solo.

Uma recomendação importante é a de que os agricultores devem retirar os frutos de pêssego danificados não colhidos e que são deixados no pomar, pois estes podem servir como fonte para a multiplicação de D. suzukii.

Com a rápida multiplicação e dispersão da praga no Rio Grande do Sul, os fruticultores devem ficar atentos e realizar o monitoramento em seus pomares, uma vez que ainda não se tem uma forma efetiva de controle para este inseto.

\section{REFERÊNCIAS}

Tabela 2. Número médio (mínimo e máximo) de adultos de D. suzukii emergidos por fruto de pêssego. IFRS - Campus Bento Gonçalves, 2016

\section{Tratamentos*}

\section{Número médio (mínimo e máximo) de adultos de D. suzukii emergidos por fruto}

Tratamento 1

Tratamento 2

o (o e o) b

Tratamento 3

o (o e o) b

Tratamento 4

$2,32$ (o e 33$) \mathrm{ab}$

10,74 (o e 234) a

Médias seguidas pela mesma letra não diferem entre si pelo teste de Tukey a $5 \%$ de probabilidade de erro. *Tratamento 1 : frutos coletados das plantas da borda do pomar; Tratamento 2: frutos coletados das plantas do interior do pomar; Tratamento 3: frutos caídos coletados no solo na borda do pomar; e Tratamento 4 : frutos caídos coletados no solo no interior do pomar.

Tabela 3. Razão sexual de adultos de D. suzukii emergidos de frutos de pêssego da cultivar Chimarrita. IFRS - Campus Bento Gonçalves, 2016.

\begin{tabular}{cccc}
\multicolumn{1}{c}{ Tratamentos* } & Fêmeas & Machos & Razão Sexual \\
Tratamento 3 & 76 & 40 & 0,65 \\
Tratamento 4 & 480 & 58 & 0,89
\end{tabular}

* Tratamento 3: frutos caídos coletados no solo na borda do pomar e Tratamento 4: frutos caídos coletados no solo no interior do pomar. 
Alston, D., R. Davis \& C. Vorel, 2010. Spotted Wing Drosophila. Utah Plant Pest Diagnostic Laboratory, Utah State University, fact sheet no. ENT-140-10, Disponível em: <http://extension. usu.edu/files/publications/publication/ENT-140-10.pdf $>$.

Bellamy, D.E., M.S. Sisterson \& S.S. Walse, 2013. Quantifying host potentials: Indexing postharvest fresh fruits for spotted wing drosophila, Drosophila suzukii. Plos One, 8: e61227. 2013. DOI: https://doi.org/10.1371/journal.pone.0061227.

Bruno, D.F.V., 2014. Comparação de dispositivos e iscos para monitorização de Drosophila suzukii (Matsumura) (Diptera: Drosophilidae) em pequenos frutos. Dissertação de Mestrado. (Mestrado em Engenharia Agronómica - Instituto Superior de Agronomia). Handle: http://hdl.handle.net/10400.5/7423. $66 \mathrm{f}$.

Canteri, M.G., R.A. Althaus \& E.A. Giglioti, 2001. Tecnologia da informação aplicada ao agronegócio e ciências ambientais: sistema para análise e separação de médias pelos métodos Ducan, Tukey e Scott-Knott. Anais do X Encontro Anual de Iniciação Científica. Parte 1. Ponta Grossa, p. 280-281.

CPAN - Capital Press Agricultural News. New fruit pest triggers concerns. 2009. Disponível em: <http://www.capitalpress. com/content/ml-vinegar-fly-092509-art>. [Acesso em: 09.vi. 2016].

Dreves, A. J. \& G.A. Langellotto-Rhodaback, 2011 Protecting Garden Fruits .from Spotted Wing Drosophila. Oregon State University, Extension Service.

Fachinello, J.C., M.S. Pasa, J.D. Schmtiz, D.L. Betemps, 2011. Situação e perspectivas da fruticultura de clima temperado no Brasil. Revista Brasileira de Fruticultura, 33: 109-120. DOI: https://doi.org/10.1590/s0100-29452011000500014.

Gerdeman, B. S., L.K. Tanigoshi \& G. Hollis Spitler, 2011. Spotted Wing Drosophila (SWD) monitoring, identifying and fruit sampling. Pullman: Washington State University, 3 p. Disponível em: <https://www.mgfsjc.org/ uploads/6/3/9/9/63992039/spottedwingdros.pdf $>$.

IBGE, 2014. Produção Agrícola Municipal. Disponível em: <http://www.sidra.ibge.gov.br/bda/pesquisas/pam/default. asp>. Acesso em: 03.vi.2016.

Lee, J.C., Denny J.B., H. Curry, D. Edwards, D.R. Haviland, R.A. Van Steenwyk, B.M. Yorgey, 2011. The susceptibility of small fruits and cherries to the spotted-wing drosophila, Drosophila suzukii. Pest Management Science, 67: 13581367. DOI: https://doi.org/10.1002/ps.2225.

Maiguashca, F., H. Ferguson, B. Bahder, T. Brooks, S. O’Neal \& D. Walsh, 2010. Spotted wing Drosophila, update: injured and ripening fruit may become more attractive: Monitoring strongly recommended. Washington State University Extension.

Nava, D.E. \& M. Botton, 2010. Bioecologia e controle de Anastrepha fraterculus e Ceratitis capitata em pessegueiro. Pelotas. Embrapa Clima Temperado, 29 p. Handle: http://www.infoteca.cnptia.embrapa.br/infoteca/handle/ doc/889693.

Santos, R.S.S., 2014a. Ocorrência de Drosophila suzukii (Matsumura, 1931) (Diptera, Drosophilidae) atacando frutos de morango no Brasil. Comunicado Técnico Embrapa Uva e Vinho, Bento Gonçalves, (Infoteca-e). 4 p. Handle: http://www.infoteca.cnptia.embrapa.br/infoteca/handle/ doc/992353.

Santos, R..S., 2014b. Drosophila suzukii (Matsumura, 1931) (Diptera: Drosophilidae) atacando frutos de morangueiro no Brasil. Enciclopédia Biosfera, Centro Científico Conhecer. Goiânia, 10: 4005-4011. Disponível em: <http://www. conhecer.org.br/enciclop/2014a/AGRARIAS/Drosophila. pdf $>$.

Santos, R.S.S., J. A. B. Amaral Neto, L.A. Bizotto, G.F. Furlani, A.S. Oliveira, 2016. Ocorrência e danos de Drosophila suzukii (Diptera: Drosophilidae) em pomar de macieira. Embrapa Uva e Vinho-Comunicado Técnico (Infoteca-e), 5 p. Handle: http://www.infoteca.cnptia.embrapa.br/infoteca/handle/ doc/1041133.

Schlesener, D.C.H., J. Wollmann, A.M. Nunes, J. Cordeiro, M.S. Gottschalk \& F.R.M. Garcia, 2015. Drosophila suzukii: Nova praga para a Fruticultura Brasileira. Biológico. São Paulo, 77: 47-54.

Silveira-Neto, S., O. Nakano, D. Bardin, \& N.A. Villa-Nova, 1976. Manual de ecologia dos insetos. Piracicaba, Agronômica Ceres, $419 \mathrm{p}$.

Souza Filho, M. F., 2006. Infestação de moscas-das-frutas (Diptera: Tephritidae e Lonchaeidae) relacionada à fenologia da goiabeira (Psidium guajava L.), nespereira (Eriobotrya japonica Lindl.) e do pessegueiro (Prunus persica Batsch). Tese de Doutorado. Tese (Doutorado em AgronomiaEntomologia)-Escola Superior de Agricultura" Luiz de Queiroz”, Universidade de São Paulo. Piracicaba. 125 f. DOI: https://doi.org/10.11606/t.11.2006.tde-08052006-164406.

Stewart, T.J., X.-G. Wang, A. Molinar \& K.M. Daane, 2014. Factors limiting peach as a potential host for Drosophila suzukii (Diptera: Drosophilidae). Journal of Economic Entomology, 107: 1771-1779. DOI: https://doi.org/10.1603/ec14197.

Teixeira, R. \& C. Rego, 2011. Drosófila da asa manchada. Boletim Técnico. Ministério da Agricultura, Mar, Ambiente e Ordenamento do Território, Universidade dos Açores.

Walsh, D.B., M.P. Bolda, R.E. Goodhue, A.J. Dreves, J. Lee, D.J. Bruck, V.M. Walton, S.D. O’Neal \& F.G. Zalom, 2011. Drosophila suzukii (Diptera: Drosophilidae): invasive pest of ripening soft fruit expanding its geographic range and damage potential. Journal of Integrated Pest Management, 2: G1-G7, DOI: https://doi.org/10.1603/ipm10010.

\section{Suggestion citation:}

Foppa, F., R.S. Borba, T. Secretti, A. Bortoncello \& J. Frare, 2018. Ocorrência de Drosophila suzukii (Matsumura) (Diptera, Drosophilidae) na cultura do pessegueiro, em Farroupilha, na Serra Gaúcha, RS. EntomoBrasilis, 11 (3): 178-184.

Available on: doi:10.12741/ebrasilis.v11i3.763
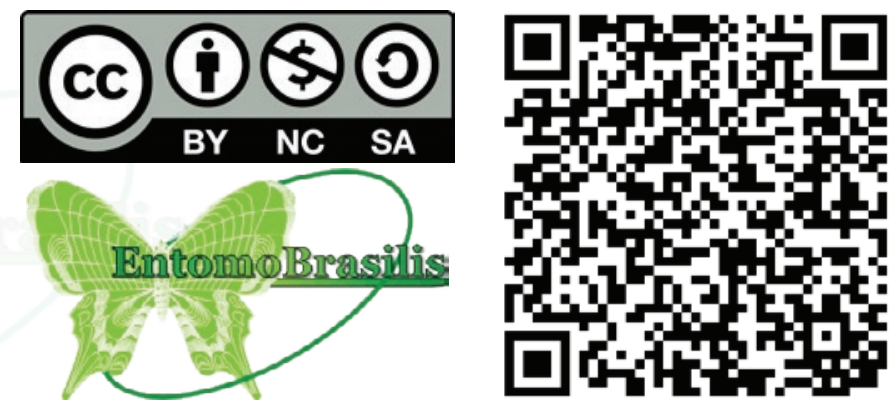